\title{
PIGMENT SPREAD AND CELL HEREDITY IN GUINEA-PIGS' SKIN
}

\author{
R. E. BILLINGHAM and P. B. MEDAWAR \\ Department of Zoology, Birmingham University
}

Received 7.xi.47

\section{INTRODUCTION}

THE phenomenon that forms the subject matter of this paper was first described by Carnot and Deflandre in 1896 and independently confirmed by Leo Loeb in 1897 . If black skin from a spotted guineapig is grafted to a white area on the same animal, the white skin surrounding the black graft blackens from its margin of contact radially outwards. Conversely, white skin grafted to a black area blackens from its periphery inwards.

Desultory attempts have been made to interpret this phenomenon since its first description 50 years ago (Sale, I9I3; Seelig, I9I3; Seevers and Spencer, I932 ; Saxton, Schmeckebier and Kelley, I936; Lewin and Peck, I94I ; Kelley and Loeb, I939; Fessler, I94I; Loeb, I945; Barker, 1947), but they have been handicapped by an incomplete knowledge of the structure of normal skin. Billingham and Medawar (I947 $a$ and $b$ ) found it possible to dispose of current theories about the nature of the blackening process and to suggest that it involves an infective cellular transformation, i.e. a conversion of cells of one true-breeding type into cells of another true-breeding type by a serially transmissible process formally similar to a virus infection. The object of this paper is to set out the evidence for this new theory in full.

\section{THE STRUCTURE OF GUINEA-PIG'S SKIN}

In crude anatomy, guinea-pig's skin consists of three major layers : (a) a fully stratified epidermis (plate I, fig. I) of composite origin ; (b) a thick dermis closely knit to $(c)$ a layer of striped muscle, the "panniculus carnosus". The principal blood vessels and lymphatics of the skin run between layers $(b)$ and $(c)$, but the guinea-pig lacks the fascial layer of connective tissue fibres that makes the skin of the rabbit strip away so easily at this level, or the layer of fat that makes it so difficult to strip away the skin of the mouse.

The epidermal layer is penetrated from below by upwardly directed extensions of the dermis, the dermal papillæ. The pattern of the hills and valleys so formed may be seen at a glance by removing the epidermis from the dermis, laying it upon its cuticular side, and thus inspecting it from below. In the integumentary skin of the 
abdomen and chest the epidermal ridges are broad and shallow (plate I, fig. 2) and run dorso-ventrally, each ridge occasionally making $\mathrm{V}$ - or Y-shaped junctions with its neighbours. The ridges of dorsal ear skin (plate I, fig. 3) are deeper and more closely spaced, and unions between neighbouring ridges are correspondingly more common. The thick and deeply stratified epidermis of the sole of the foot forms a very fine even meshwork - in effect, a partially perforated plate-through the holes in which the peg-shaped dermal papillæ pass far upwards into the substance of the epidermal layer (plate I, fig. 4).

\section{(i) Pigmented skin}

Black guinea-pig skin owes its colour to melanin granules in the superficial epidermis, the epidermis of the hair follicles, and the medulla of the hairs. (In rabbits and mice, by contrast, melanin granules are absent from the superficial epidermis of integumentary skin.) Pigmented epidermis reveals its composite nature very clearly when examined from below. Its cellular components are :

(a) Ordinary epidermal cells, together with their derivatives by fission and subsequent keratinisation which form the upper strata of the epidermis.

(b) Pigmentary dendritic cells or melanophores* which are located in the basal layer of the epidermis, though their cell bodies may sometimes intrude into the dermis below them (plate I, figs. 5, 6, 7). From their nucleated cell bodies arise a modal number of five or six primary branches which, repeatedly subdividing, weave horizontally and upwards between the ordinary epidermal cells that surround them (Billingham and Medawar, 1947b ; Billingham, 1948). The branches, which may extend up to $100 \mu$ from the parent cell body, each end in a cup-shaped button very intimately applied to the surface of an ordinary epidermal cell of the basal or "prickle" layers. In any pure epidermal ("split skin" : see below) preparation that is studied closely enough it will be found that a branch from some dendritic cells will form an end-cap, not on an epidermal cell within its reach, but on the cell body of a neighbouring dendritic cell. Less frequently, the branches of neighbouring dendritic cells may be confluent; but this may represent only the temporary aftermath of a recent cell division. (Division stages of dendritic cells have been figured by Billingham, r 948 .)

Pigmentary dendritic cells are most densely concentrated at the bases of the ridges or bulges into which the epidermis is thrown by the upward penetration of dermal papillæ or dermal pegs (plate I,

* To avoid misunderstanding the term "melanophore" will be used, in this paper only, as a convenient abbreviation for "pigmentary dendritic cell"; but we hope that our more precise descriptive term will come into general use. The homology of fish and amphibian melanophores with mammalian dendritic cells, though likely, has yet to be demonstrated. The change of terminology we recommend has been made necessary by the discovery of the non-pigmentary dendritic cell (see below). 
figs. 2, 3, 4). Their spacing here is such that each dendritic cell is within arm's reach of its neighbours, so that they are capable of forming a contiguous system ; but it is doubtful if they can do so at the tops of the ridges of integumentary skin, where their distribution is rather more sparse (plate I, fig. 2).

The second principal accumulation of dendritic cells occurs in the hair bulbs, which are often so thickly jacketed by pigment as to be optically impenetrable. Hair bulb and the basal layer of the superficial epidermis are, of course, continuous through the outer root sheath of the hair ; but the concentration of dendritic cells falls off from the base of the follicle towards its opening, so that dendritic cells are either wholly absent from the follicle neck in the region where the sebaceous glands open into it (plate I, fig. 8), or are so sparse that they do not form a contiguous system. In the majority of mature follicles they are altogether absent from this region of the neck.

Melanin granules are found both in pigmentary dendritic cells and in ordinary epidermal cells (plate I, fig. 9) ; but it has been agreed by all students of skin pigmentation in mammals and birds (Dorris, I939 ; Eastlick, I939 ; Hamilton, I94I ; Rawles, I940, I947; Ginsburg, 1944) that only the former are capable of making melanin. The process by which formed melanin granules are passed from the branches of pigmentary dendritic cells into the cytoplasm of ordinary epidermal cells is not yet understood, though it must clearly be mediated by the cup-shaped buttons in which the branches end. Every stage may be distinguished between the formation of end-buttons on the surfaces of epidermal cells; the extrusion of melanin granules formed in them to make a layer over the nucleus ( $c f$. plate I, fig. 9); the breaking away of the buttons from parent branches; and the slow diffusion of melanin granules through the cytoplasm of the cells into which they have thus penetrated (Billingham, I948). Whatever the exact physical mechanism may be, it is clear that pigmentary dendritic cells are capable of entering into the most intimate cytoplasmic connections with ordinary epidermal cells ; and it may be presumed that they form equally intimate connections with such other dendritic cells as their branches may end on, since their branches are applied to them in exactly the same way.

Pigmentary dendritic cells turn an intense even black if immersed for $3^{-6}$ hours at $37^{\circ} \mathrm{C}$. in I : I,00o,ooo solution of $3: 4$-dihydroxyphenylalanine in $\mathrm{M} \cdot 6 \mathrm{o}$ phosphate buffer at $p \mathrm{H} 7 \cdot 4$; i.e. they are dopa-positive (Bloch, I927, I929; Percival and Stewart, I930; Laidlaw and Blackberg, I932). It is not universally believed either that dihydroxyphenylalanine is a natural oxidation product of tyrosine and precursor of melanin (see review by Meirowsky, 1940) or that the dopa-reaction indicates the presence of a single specific enzyme. There is no doubt, however, that it can be used as an indicator of pigmentary function in the cells of the epidermis (Russell, I939; Ginsburg, 1944). 


\section{(ii) White skin}

The white skin of the spotted guinea-pig is, of course, colourless ; but it differs from the white skin of the "albino" guinea-pig and of the human being in that neither extreme cold nor any known form of traumatic or actinic irritation can induce any shadow of pigmentation in it ( $c f$. Lewin and Peck, I94I ; Ginsburg, I944). Correspondingly, no element of the white epidermis is dopa-positive (Russell, r939; Ginsburg, 1944). (The ears and other points of even albino guineapigs darken in cold weather ; and dendritic cells, until then invisible, show up boldly in split preparations of their skin.)

The examination of split white skin (i.e. the epidermis freed from dermis), either as an intact sheet or as squashes or macerates of various degrees of fineness, reveals no element corresponding to the dendritic cell of pigmented skin by either normal or phase-contrast microscopy. The existence of a non-pigmentary analogue was nevertheless predicted by our hypothesis on the nature of the colour transformation, and was discovered (Billingham, I948; $c f$. Billingham and Medawar, 1947b) by applying a gold-impregnation technique designed for showing up the finer endings of cutaneous nerves (Gairns, 1930). The appropriate variant of Gairns' technique has been described in full by Billingham (1948). Area for area, non-pigmentary dendritic cells (plate II, figs. 10, II) resemble their pigmentary analogues in every respect save that they are dopa-negative and neither form, nor can be induced to form, melanin granules. They are similar in size, form, number, and distribution; in the pattern and length of branching; and in their manner of termination upon the "ordinary" epidermal cells of their domain. As with pigmentary dendritic cells, branches arising from one cell may end in a characteristic cap upon the cell-body of another; and, more rarely, the branches of neighbouring nonpigmentary dendritic cells are confluent.

Dendritic cells as a class-they are easily identifiable without special staining techniques in brown or red guinea-pig skin, as well as black-must therefore be regarded as a constant ingredient of the epidermis of the guinea-pig, as of the human being (Langerhans, I868; Billingham, r948).

There is, however, one member of the variegated family of epidermal epithelia in which it has not been possible to demonstrate dendritic cells ; the epithelium of the tongue. Pigmentary dendritic cells are likewise absent, for we have found no instance of naturally occurring pigmentation in the guinea-pig's tongue. The absence of dendritic cells from the guinea-pig's tongue has been made the basis of a critical experiment (see below).

\section{METHODS}

\section{(i) Histological methods}

The pure epidermal sheet that we have called "split skin," comprising the whole of the epidermis and nothing but the epidermis, 
is prepared by dissolving away the elastic fibres that unite it to the dermis (Medawar, I94I). To secure an efficient splitting of epidermis from dermis it is essential that the skin slices should be as thin as possible and of even thickness. The handling of such thin razor slices is simplified by smearing the outer surface of the skin with vaseline before removal ; they may then be floated on a Seitz-filtered 0.5 per cent. solution of commercial trypsin powder in Ringerbicarbonate containing I : I00,000 phenol red and adjusted thereby to $p \mathrm{H} 7 \cdot 8$. Digestion for $20-30$ minutes at $38^{\circ} \mathrm{C}$. is sufficient for the thinnest even slices, but may be prolonged to 2 hours without killing the cells. The slices may then be rinsed by flotation in Ringer's solution and laid with their cuticular surface down. The dermis is withdrawn simply by lifting it off with fine forceps. It may be added that a I per cent. solution of commercial papain powder activated by 0.2 per cent. cysteine- $\mathrm{HCl}$ and adjusted by $\mathrm{N} /$ Io $\mathrm{NaOH}$ to $p \mathrm{H} 6.5$ is equally effective, but has no apparent advantage. Pepsin solutions are ineffective.

The epidermal sheet prepared by tryptic splitting is morphologically intact (plate II, figs. I2, I3). That its cells are still alive is proved beyond possibility of error by the fact that a graft of split black skin transplanted to a large raw area cut from white skin heals on, proliferates, and continues to form pigment. Other thermal, mechanical or chemical methods of splitting away the epidermis (cf. Baumberger, Suntzeff, and Cowdry, 1942 ; Cowdry, I943; Suntzeff and Carruthers, I946) either destroy the architecture of skin or kill the epidermal cells.

Sections of split black skin reveal dendritic cells more clearly than sections of full thickness (plate II, fig. I3).

As a general histological routine we have employed fixation by formol- $\mathrm{HgCl}_{2}$ or Bouin's solution, dehydration in an ethyl alcohol series, clearing in cedar-wood oil followed by ligroin, and imbedding in paraffin wax. Wherever it has been possible, however, we have preferred to study living material.

\section{(ii) Operative methods}

" Pigment spread," as the process may non-committally be called, takes place during a spotted guinea-pig's normal life at the margin of contact between pigmented and white areas. In a newly-born guineapig, black skin bearing black hair is sharply. separated from white skin bearing white hair; but in the adult there is a characteristic transitional zone (see below, and plate II, fig. I6) of blackened skin bearing white hairs. The normal rate of pigment spread is unworkably slow : a grafting operation $(a)$ speeds the process up, since grafting is followed by a prolonged period of increased cellular and vascular activity in the graft and its neighbourhood; and $(b)$ brings it under experimental control. In all but a few experiments clearly 
distinguished below, autografts alone have been used-i.e. grafts from one part to another of the same individual. Claims in the earlier literature that grafts from one individual to another, homografts, do or do not participate in pigment spread need not detain us here. There is no acceptable evidence that a black skin homograft can induce pigmentation in the white skin of its recipient. A white skin homograft in a black area will in due course certainly darken, but merely as a consequence of the invasive replacement of graft epidermis by native epidermis during the former's breakdown (Medawar, 1944).

Special techniques of grafting (e.g. to or from the foot or tongue) will be mentioned as they come up for consideration in the text. The basic technique is a variant, adapted to the guinea-pig, of that used in the rabbit and fully described by Medawar (1944, 1945). Discs of skin up to $\mathrm{I} \mathrm{cm}$. in diameter and comprising the full thickness of the dermis, pinch grafts, may be cut from any skin area and grafted to the skin overlying the right or left sides of the chest, where the ribs offer a firm substratum (plate II, fig. I4). The graft should as a rule fit exactly into a hole cut to receive it ; in effect, into the hole left behind by cutting from the recipient area a pinch graft slightly smaller than the one intended to take its place. When the graft is in position, it is covered successively by $(a)$ a $2 \mathrm{~cm}$. square of vaselineimpregnated fine mesh bandage (" tulle gras") ; $(b)$ a 3-4 cm. square of Elastoplast which overlaps the tulle all round and, being firmly applied to the previously shaved or closely clipped skin, prevents side-slip ; and $(c)$ two strips $(2 \cdot 5-4 \cdot 0 \mathrm{~cm}$. by $30-40 \mathrm{~cm}$.) of plasterimpregnated bandage ("Gypsona") firmly wound round the thorax immediately after wetting. When the plaster dries it forms a firm but not inflexible protective jacket which sticks to the hairs beneath it, though not to the graft's immediate dressings, and is thereby held firmly in place. Painting the dried plaster with a saturated solution of picric acid discourages the animal's attempts to gnaw it away.

Primary inspection may be made after 7-Io days, during the course of which the graft donor area heals by first intention. The plaster jacket may be peeled off without special precautions, but the Elastoplast square should be damped with ether before any attempt is made to remove it. An ingredient of the Elastoplast sometimes causes a slight inflammation of the skin, particularly if the operation field has been shaved, rather than close-clipped, on the day of grafting. If there is any noticeable reaction, it is as well to soothe the skin with vaseline or gentian violet jelly. Otherwise the guinea-pig may be provoked into scratching the operation field and damaging the graft.

After the primary inspection it is well worth while protecting the young graft by twisting three turns of $4 \mathrm{~cm}$.-wide plain bandage round the thorax and sealing it in place with one strip of plaster bandage. This temporary dressing may be removed after a further 5-7 days. No other is required. 
The dressing technique we have described was worked out after a great many preliminary trials, and we are satisfied that no part of it can be omitted without prejudicing the success of the grafts.

\section{THE PHENOMENON OF PIGMENT SPREAD}

In this section we shall outline our basic observations on the spread of pigmentation in the body skin of spotted guinea-pigs. A study of 12 white-in-black or black-in-white skin autografts in spotted mice had already revealed no trace of pigment spread after Ioo days, and two similar experiments with rabbits revealed no spread after more than 150 days. The fact that pigmentary and non-pigmentary dendritic cells are alike absent from the superficial epidermis of the body skin of rabbits and mice reinforces our conclusion (see below) that the spreading phenomenon is mediated by dendritic cells.

After transplanting a pinch graft of white skin to a black area, or vice versa, there is a latent period of spread lasting 20-30 days, during the course of which the graft heals in, settles down (in the sense that the characteristic initial outburst of cellular and vascular proliferation subsides), and grows a full pelt of hairs of graft-specific colour, stoutness, density and orientation. (In the period 8-I6 days, corresponding to the time of maximal mitotic activity in the epidermis — cf. Medawar, 1944-black skin grafts undergo a very decided but merely transient blanching.) If the graft has been very exactly fitted to its recipient area, the margin between black skin bearing black hairs and white skin bearing white hairs is incisive. The first indication of pigment spread is the blurring of this margin. Spread of pigmentation in the superficial epidermis then goes on progressively, in the manner illustrated by the accompanying series of cellophane tracings (fig. I), at a rate which, in the case of black-in-white grafts, falls off from something of the order of I mm. per week to I $\mathrm{mm}$. per month or less. The inwards spread in the case of a white-in-black graft is about half as fast. In either case, spread will for all practical purposes have stopped after a year, though it may be renewed at any point at or within the perimeter of the blackened area by cutting or irritating the skin. Correspondingly, the rate of spread is slightly but significantly increased by painting the skin with an irritant (e.g. turpentine and acetone in equal mixture : Rous, 1946) which maintains a hyperplastic condition of the epidermis. Repeated shaving does as much.

The principal characteristics of the spreading phenomenon in body skin (plate II, figs. I5-I8, and $c f$. plate IV, fig. 26) are these. (A) The hairs of artificially blackened white skin remain white, and sections of such skin show that melanin granules are confined to the superficial epidermis-mainly to the dendritic cells. By repeated trauma-most conveniently by repeated serial grafting (see below)it is however possible to induce the formation of up to Io per cent. of 


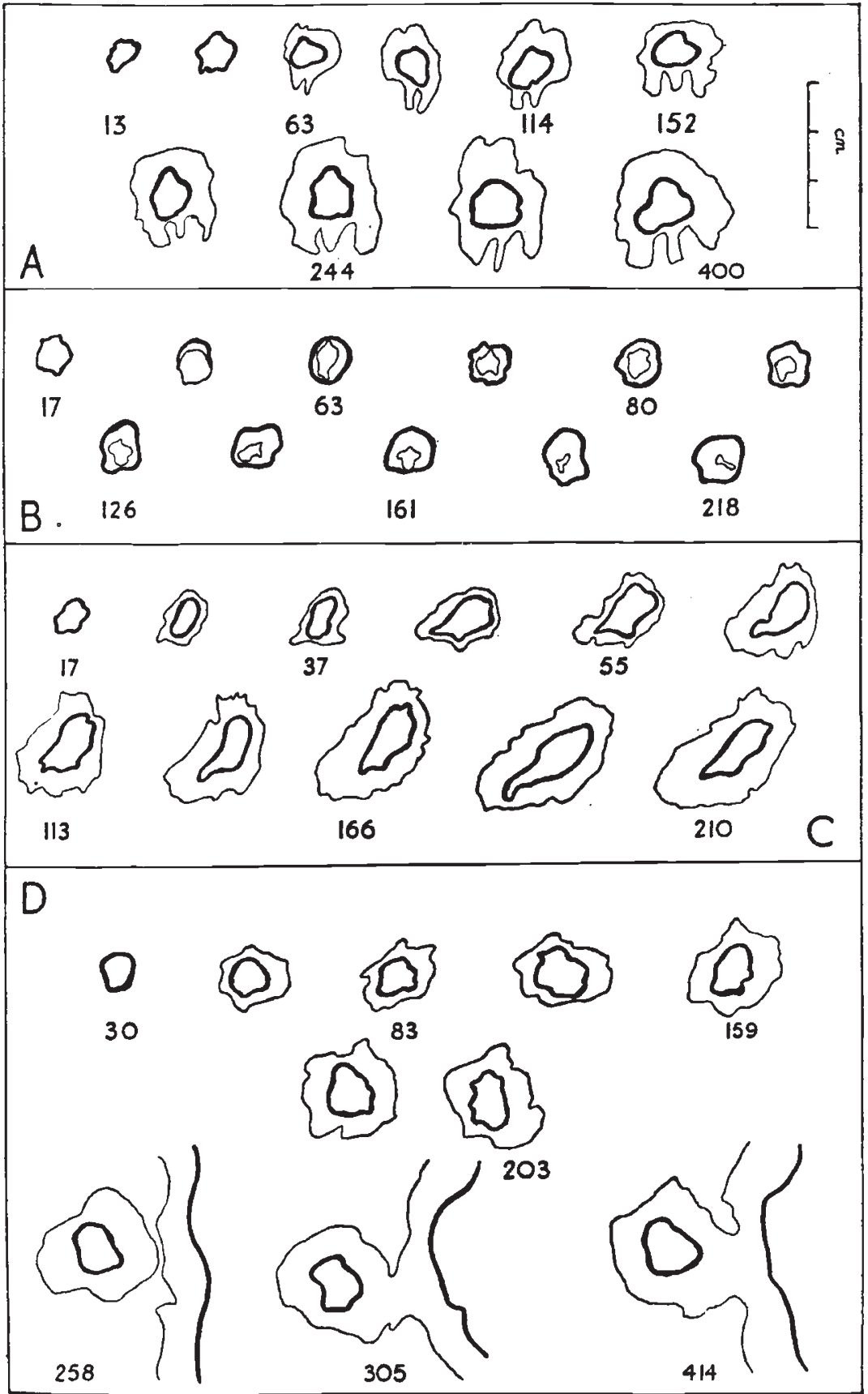

FIG. I.-Series of direct celluloid tracings illustrating the progress of pigment spread in black-in-white grafts (A, C, D) and in a white-in-black graft (B). Confluence with the transition zone of normal spread is illustrated by the last three tracings in (D). The numbers refer to days since transplantation. All figures have been drawn to the same scale. 
black hairs from superficially blackened white skin. (B) Pigment spread is reticulate, not homogeneous in pattern : it appears in characteristic black threads and tongues running between the hair rows and near to the hair bases in the acute angle of slope, occasionally uniting in $\mathrm{V}$ - or $\mathrm{Y}$-shaped junctions. The pattern corresponds exactly with the pattern of ridges (plate I, fig. 2) in the epidermis of body skin. (C) The pattern of spread is uniformly reticulate over the whole area of artificial pigmentation; i.e. it is no denser at the centre than at the periphery.

If a graft is not fitted exactly to its recipient area, but is surrounded on planting by an annulus of unsurfaced skin bed, the appearance is at first a little different. The raw annulus is rapidly surfaced by migratory outgrowth of epithelium from the graft accompanied by ingrowth from the margins of the raw area. Since this epithelium is abnormally thick, the resurfaced annulus will appear blacker than the graft or the surrounding skin, whichever was black in the first instance.

Pigment spread may be initiated by grafts of split black skin (i.e. of the pure epidermis) to white areas. Conversely, split white skin is blackened after grafting to a black area. It follows that initiation of, and response to, artificial blackening is secured by cellular elements of the epidermis alone, although it still might be possible for the dermis or fibrous substratum to mediate the process, e.g. by acting as a thoroughfare for the migration of cells out of and into the epidermal layer. It may be added that any surviving tag of black skin, representing the fractional remainder of a badly executed graft, may prove to act as the centre of origin of pigment spread.

In seven independent trials we have recorded no instance of pigment spread being initiated by a black skin homograft, however small. Other things being equal, the survival time of a homograft varies inversely with the amount of foreign tissue that is grafted (Medawar, 1944, I945). We therefore used the smallest grafts possible-squares of less than I $\mathrm{mm}$. in length of side-in order to prolong their life as homografts to its maximum extent. Part of the theoretical advantage of using such small homografts is offset by the fact that, when tucked intradermally, as their minute size requires them to be, their epidermis takes an abnormally long time to become confluent with the native epidermis above. Some grafts encyst themselves and fail to do so altogether. Nevertheless, four of five autografts transplanted in exactly similar fashion became centres of origin of pigment spread, and the consolidation of intradermal homografts with native skin was made evident in one case by its piercing the surface to form two isolated black hairs. Only two of the intradermal autografts grew hairs in this fashion. 


\section{SYSTEMATIC ANALYSIS OF THE PHENOMENON}

In this section, four hypotheses concerning the nature of pigment spread will be considered in turn.

(I) Invasive cellular replacement. Black skin is "dominant to" or "stronger than" white; and when the two are juxtaposed, black epidermis invades and replaces white epidermis, much as native epithelium will invade and replace the degenerating epithelium of a skin homograft. This is Loeb's theory ( $c f$. Loeb, I945).

(II) Diffusion. White skin lacks some essential enzyme, co-enzyme, or metabolic intermediary that is essential for making melanin. This diffuses from black skin into white across epidermal cell interfaces or " bridges," and so endows white skin with pigmentary function. A variant of this theory was considered by Lewin and Peck (I94I). Alternatively, white skin is fully equipped to manufacture melanin, but is prevented from doing so by an inhibitory substance. What diffuses from black skin into white is an anti-inhibitor.

(III) Melanophore migration. The phenomenon of spread is brought about by the active differential migration of pigmentary dendritic cells from black skin into white. This hypothesis has been considered in passing by many authors, and only the lack, until now, of suitable methods for studying their structure and distribution has denied it a stronger championship.

(IV) Infection. Pigment spread involves a cellular transformation of the "infective" type. By "cellular transformation" is implied that certain non-pigmentary cells of white skin are converted into pigment-forming cells, in such a manner that they, and their lineal descendants by mitotic fission, remain pigmentary in function thereafter ; and by "infective" is meant that the transformation is serially transmissible, so that one cell infectively transformed may in its turn transform another ( $c f$. Medawar, I947).

\section{(i) The hypothesis of invasive replacement}

The refutation of this hypothesis turns upon the fact that the various races of epidermal epithelia are strictly true-breeding in their mitotic lineage, and so conserve their specific differences indefinitely on heterotopic transplantation, i.e. transplantation to anatomically unnatural positions. Even the smallest pinch grafts of sole-of-foot, tongue, and claw-forming epithelium do, indeed, preserve their very distinctive graft-specific characters in any position to which they can be successfully transplanted ( $c f$. plate III, figs. I9-24; plate IV, figs. 26-3o, 32). But if hypothesis (I) is correct, the outcome of a heterotopic transplantation of (say) white sole-of-foot epidermis into black body skin is at once predictable: black body-skin epidermis will invade and replace white sole-of-foot epidermis, forming in the outcome a graft surfaced by the epithelium characteristic of body skin. 
This does not in fact happen. If a pinch graft is cut from a white sole and transplanted to black chest skin (plate III, fig. I9) the graft duly blackens; but it remains a sole-of-foot graft, with its characteristically high growth rate and deep epidermal stratification. Pads of compact cuticle, which in normal life would be worn away, can be removed from the graft weekly. In vertical section (plate III, figs. 2O, 2I) the margin between integumentary and sole epithelium is absolutely incisive.* Once blackened in this way, moreover, a sole-of-foot graft may be returned to its original environment, where it converts the surrounding white sole into what is indisputably a black sole (plate IV, fig. 25).

In just the same way, the lunula (claw-forming area) of a white claw (plate III, fig. 22; and see le Gros Clark, I936) may be transplanted bodily to black thoracic skin; whereupon it turns relatively rapidly (30-50 days), not into black skin, but into a black claw. Here, as before, the boundary between the two types of epithelia can be distinguished almost to a cellular interface (plate III, figs. 23, 24). White vagina epithelium does not lend itself so well to this demonstration, since its differences from integumentary skin are not so clean-cut; but an artificially blackened white vaginal graft conserves its characteristic surface appearance and cellular stratification.

These experiments constitute a decisive refutation of the hypothesis of invasive replacement, which will not be referred to again.

\section{(ii) The diffusion hypothesis}

There is nothing fundamentally implausible in the idea that an enzyme or co-enzyme diffuses from one epidermal cell into another. The variant of the hypothesis which postulates the diffusion of an anti-inhibitor is perhaps slightly more acceptable, because white human skin, which can manufacture melanin, seems to be prevented from doing so by an inhibitory substance (Rothman, Krysa, and Smiljanic, I946). It has already been pointed out, however, that nothing appears to be able to induce pigmentation in the white skin of spotted guinea-pigs except the spreading process initiated by black skin.

The quantitative properties of the process of spread challenge both variants of the hypothesis. The density of pigmentation does not, for example, fall off from the hypothetical diffusion centre to the periphery. The decisive objections, however, are $(a)$ that the artificial blackening of a white epithelium represents the initiation of an inherited character difference : the descendants of a cell once blackened

* The fact that the high growth rate of sole-of-foot epithelium represents an inherited somatic character difference is anticipated by genetical theory, since animals are born with thickened soles ready-made. As with so many other cases, the thickening of the sole has become a cause celebre among upholders of the theory of inheritance of acquired characters, because it is so easy to mimic phenotypically-by chronic irritation, for example. 
remain pigmentary in function over the span of a lineage which in our own experience amounts to hundreds of cellular generations; and $(b)$ the pigmentary function is serially transmissible without loss. If, following Fessler (I94I), a small part of the blackened annulus surrounding a black-in-white integumentary skin graft is removed and grafted to new white surroundings elsewhere, it duly blackens the skin about it. Part of this newly blackened annulus may again be removed and grafted to a new white environment and will again blacken it ; and so on (fig. 2). We have carried such serial transplantations to

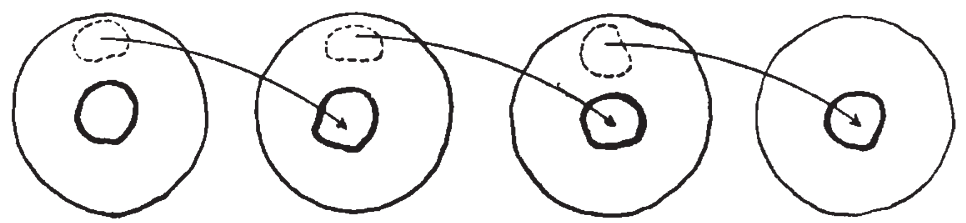

FrG. 2.-Illustrating the principle of the experiment used to demonstrate the serial propagation of pigment spread (see text).

the fourth stage, representing a dilution of the order of $I: 1000$ of the hypothetical diffusing substance of the ancestral graft. The density of pigmentation was not reduced, and its rate was revived and maintained by the repeated "activations" consequent on grafting. Moreover, pigmentation in the farthest boundary of spread from a late stage graft may be intensified at will by any form of simple injury that will cause the skin to be repaired by a temporarily thickened epithelium-a circumstance that requires the postulation of an indefinitely large reservoir of diffusing substance. In short, whatever it is that causes white skin to turn black must multiply with, or be repeatedly generated anew in, the tissue that houses it. A simple diffusion hypothesis is therefore unacceptable.

\section{(iii) The hypothesis of melanophore migration}

Since pigmentary dendritic cells (melanophores) are the acknowledged origin and seat of the pigmentary function in coloured skins, it is a reasonable guess that pigment spread represents the outcome of their differential migration from black skin into white. In early development dendritic cells do in fact migrate from the neural crest to their stations at the periphery (Rawles, 1940, 1947). This can hardly be regarded as a distinctive property of melanophores, for the newly discovered non-pigmentary dendritic cells presumably do likewise ; and, indeed, the ancestors of every cell in the body at some time migrated from their presumptive to their definitive positions.

The melanophore migration theory accounts perfectly well for the facts already considered in relation to hypotheses (i) and (ii) ; under (i) because melanophores from black body skin might well migrate into (say) white nail and so blacken it, and under (ii) because a migrated melanophore could satisfy by periodic cell division the condition that the blackening agent should proliferate in the tissue 
FIG. I.-Vertical section through pigmented guinea-pig's skin cut transversely to the hair shafts. Note the thickness and characteristic stratification of the epidermis. Hæmatoxylin and eosin. X I Io.

Figs. 5, 6, 7.-Pigmentary dendritic cells. Fig. $5(\times 600)$ is a high-power photograph of a preparation exactly similar to that illustrated by fig. 3 after subjection to dopa treatment for one hour. The preparation is unsquashed and the distribution and optical depth of the dendritic cells of ear skin is thus normal ; ordinary epidermal cells are invisible. Figs. 6 and $7(\times 550)$ are from surviving preparations of split black ear skin lightly squashed in Ringer's solution. The dendritic cells are clearly nucleate. Note that melanin granules are present in the ordinary epidermal cells round which the dendritic cell processes normally twine.

FIG. 8.--Vertical section through pigmented body skin cut very exactly in the plane of hair slope and lightly stained with carmalum and orange-G $(\times 90)$. Melanin granules and dendritic cells are wholly absent from the hair follicle neck (
FIgs. 2, 3, 4.-The epidermal ridging characteristic of body skin (fig. 2), ear skin (fig. 3), and sole of foot (fig. 4), in unstained whole mounts of the pure pigmented epidermis viewed from the underside. $\times 30$.
FIG. 9.-Isolated " ordinary" epidermal cells from deeply pigmented ear skin ( $X$ I I oo) about one hour after teasing out in Ringer's solution. Melanin granules are present in the cells in their characteristic initial nuclear cap. Cytolysis is clearly just beginning. 
FIGs. IO, I I.- - Non-pigmentary dendritic cells from the white ear skin of a spotted guinea-pig in an epidermal squash of a preparation stained by Billingham's variant of Gairns' gold-impregnation method. Note that the distribution, number, size, and mode of branching is just the same as with pigmentary dendritic cells, though fixation in 25 per cent. formic acid has caused them to appear slightly more compact and wiry. The nuclei of ordinary epidermal cells are easily visible. Non-pigmentary dendritic cells are quite invisible in the living epidermis. Fig. Io $\times 15^{0}$; fig. I I $\times 270$.

FIGs. 12, 13.- " Split" black ear skin : the pure epidermis separated from the dermis by tryptic digestion, in vertical section lightly stained by Ehrlich's hæmatoxylin and eosin. Dendritic cells are more prominent than in sections of full-thickness skin. Fig. I $2 \times$ I IO ; fig. $13 \times 500$.

FIG. 14.--Spotted guinea-pig with first and early second-stage grafts in position on the left side of the chest and spreading.
Figs. I 5, i6 (and $c f$. fig. 26). - Black-in-white body skin grafts showing the extent of pigment spread after 89 and 106 days respectively. Note that the pattern of spread is reticular but even, and that the hairs of blackened white skin remain white. In fig. 16 note the transitional zone of natural pigment spread (top left) towards which pigment from the graft is creeping. 

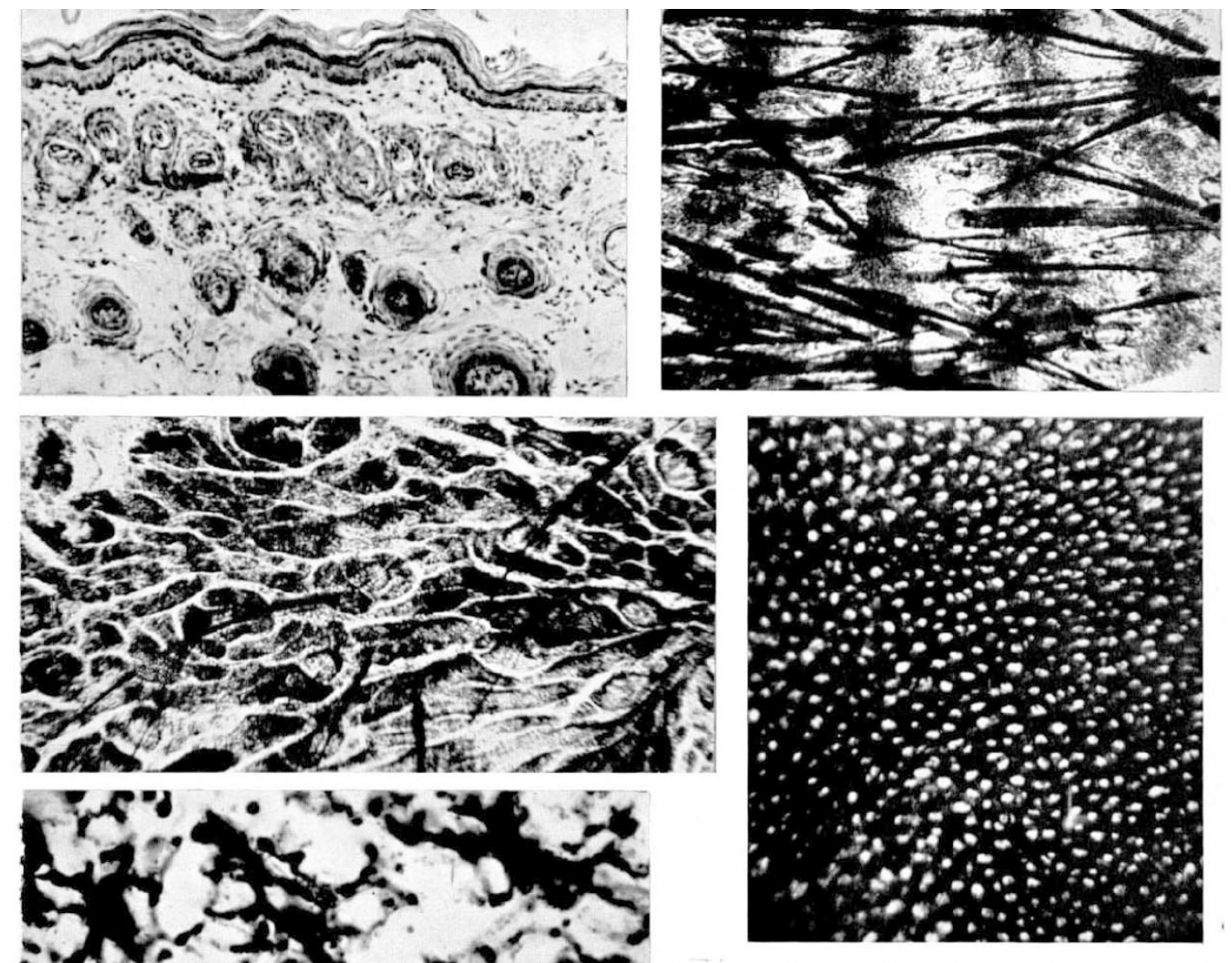

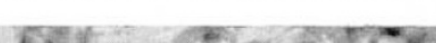

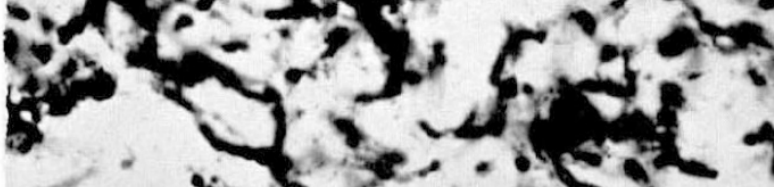
$-2+x-32$
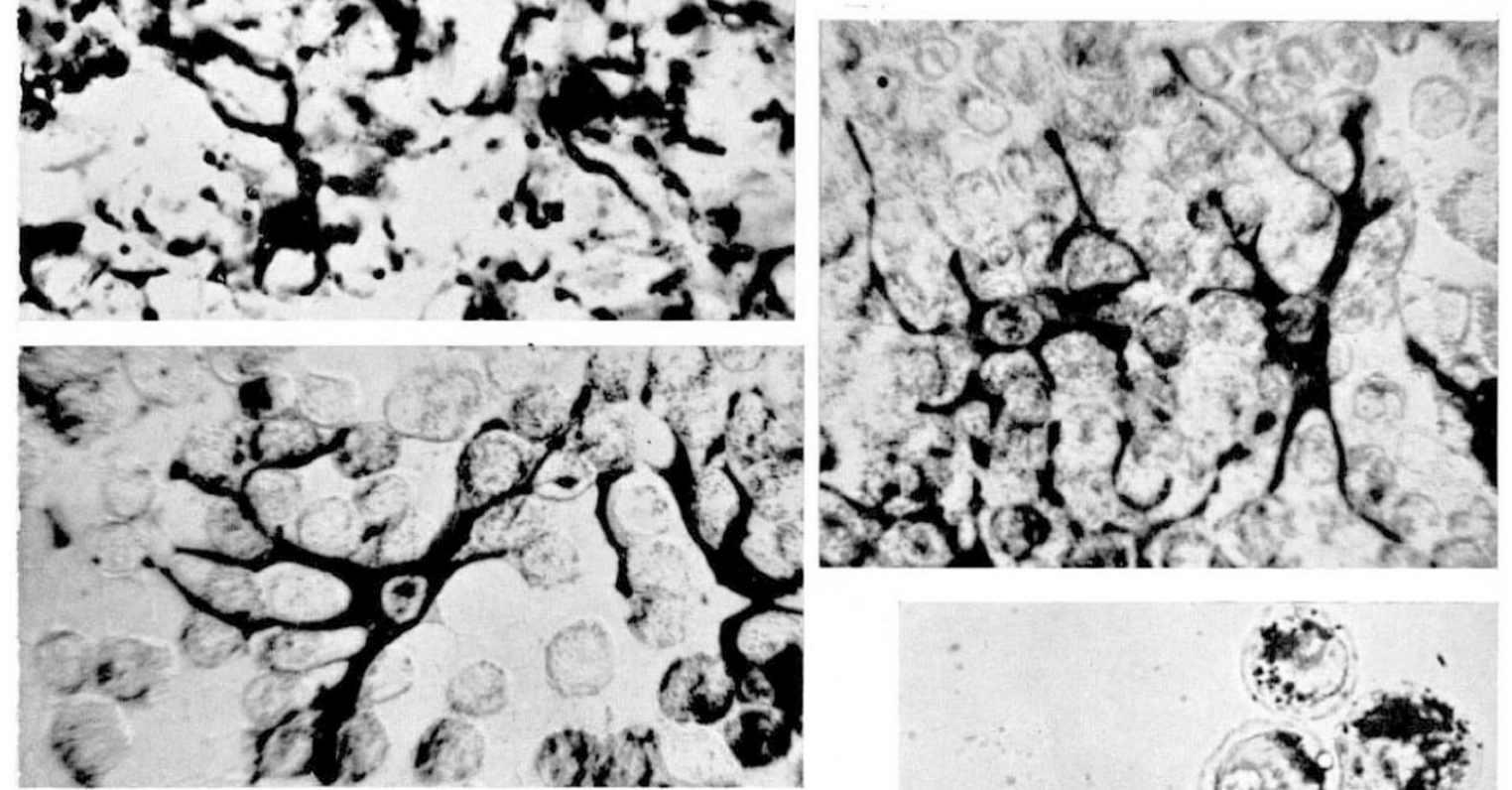
(1) 2utor. rerava
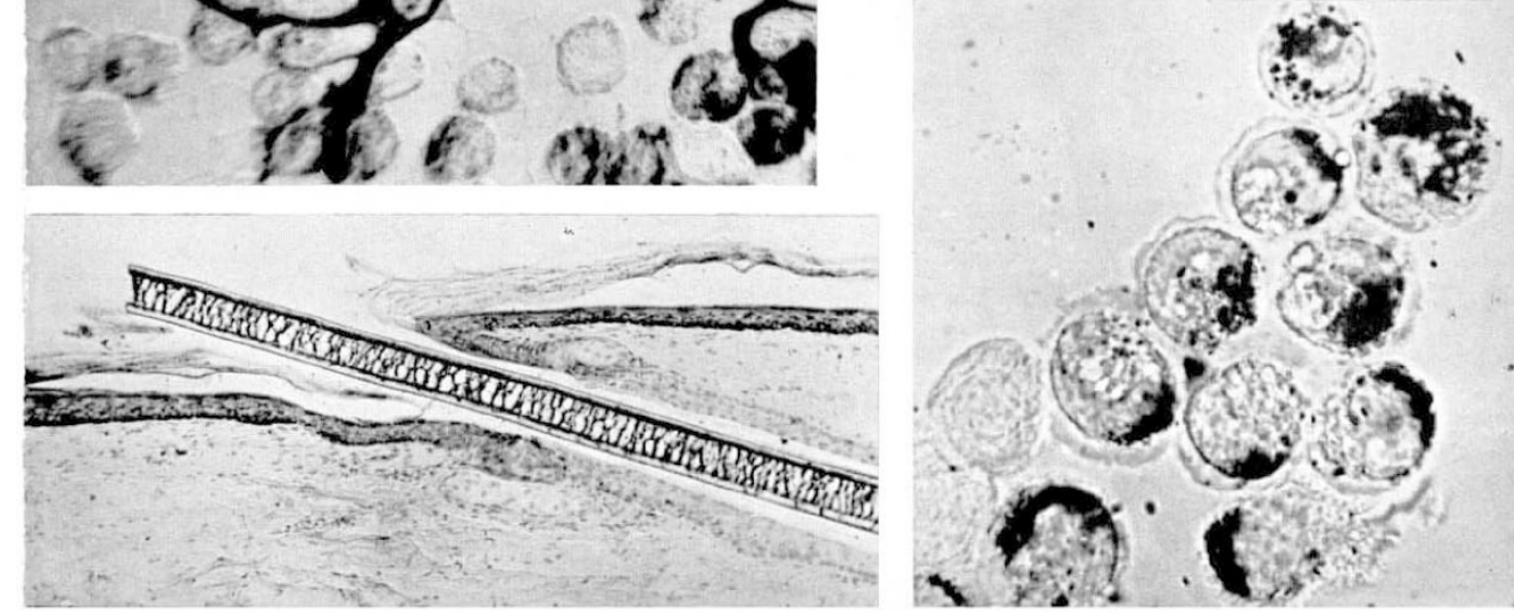


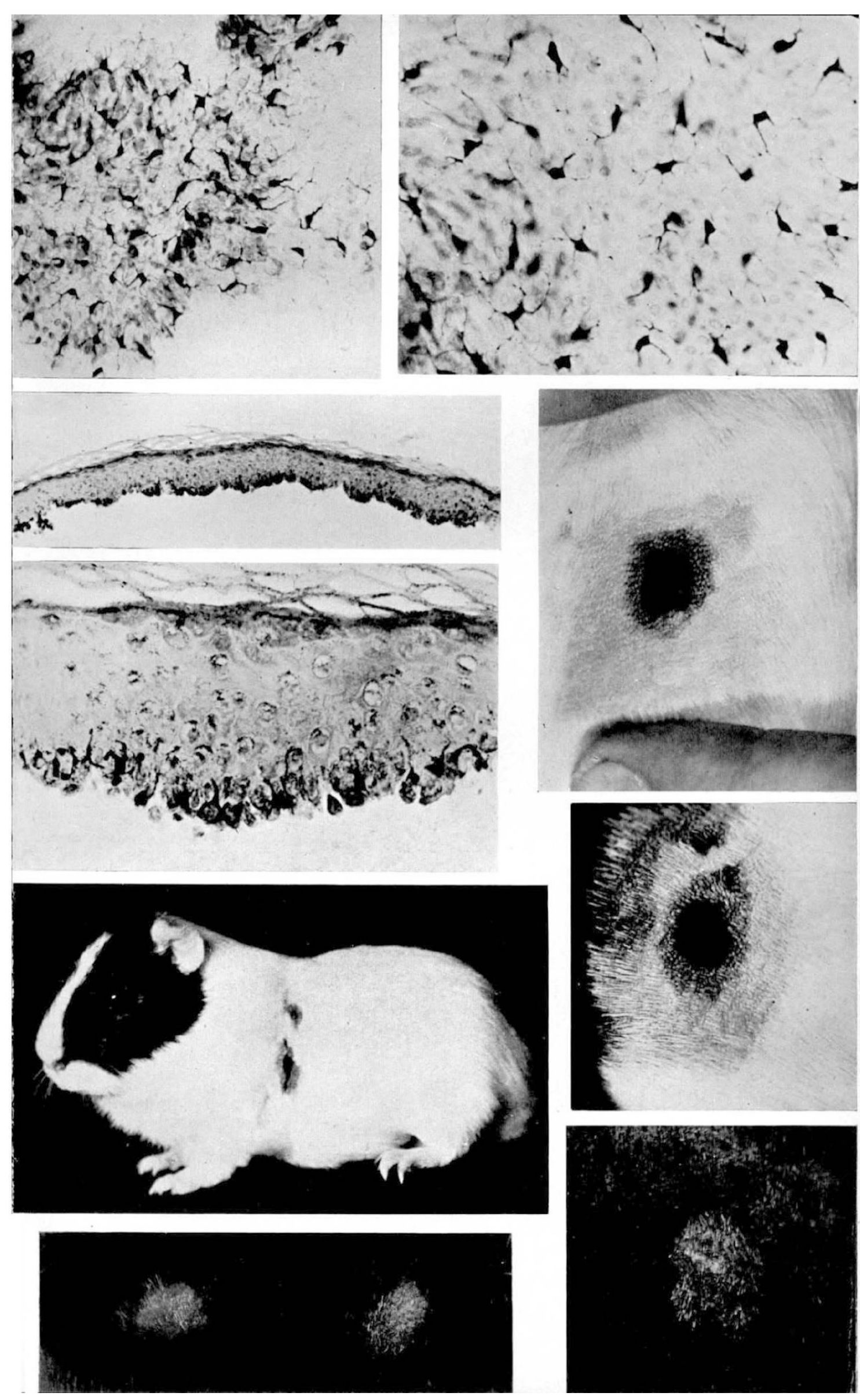


FiGs. 20, 21.-Sections through the margins of a white sole-of-foot graft in black skin (cf. fig. 19) which has undergone full blackening $5_{1}$ days after transplantation. Note the clean-cut distinction between pigmented body epidermis and the more heavily pigmented epidermis of the sole of the foot, which is still proliferating strongly and producing layer after layer of dense cuticle. Ehrlich's hæmatoxylin and eosin. $\times 110$.

F1G. 22.-Illustrating the "Iunula" of a white guinea-pig's claw, occupying the same relative position as the half-moon of human nails. Beneath the lunula lies the claw-forming epithelium.
F1G. 19.-White sole-of-foot graft 268 days after transplanting to black body skin : the graft is of course bald and heavily cuticularised, and has long since become a very dense even black. Even at this stage pads of compact cuticle, remaining attached for lack of natural wear, can be removed weekly ( $c f$. fig. 26).

FIG. 23.-Claw-forming epithelium from the lunula of a white claw (fig. 22) almost completely blackened 33 days after transplanting to black chest skin. Note the compact half-crescent of exceedingly dense claw substance. Ehrlich's hæmatoxylin and eosin. $\times 35$.

Fig. 24.-As fig. 23 ; a high-power view of the claw-skin junction $\left({ }_{1}{ }_{15} 6\right)$ showing the basal layer of the claw epidermis far more densely laden with melanin granules than the surrounding black body skin. The junction between the loose flaky skin cuticle and the tough horny claw is quite incisive. 

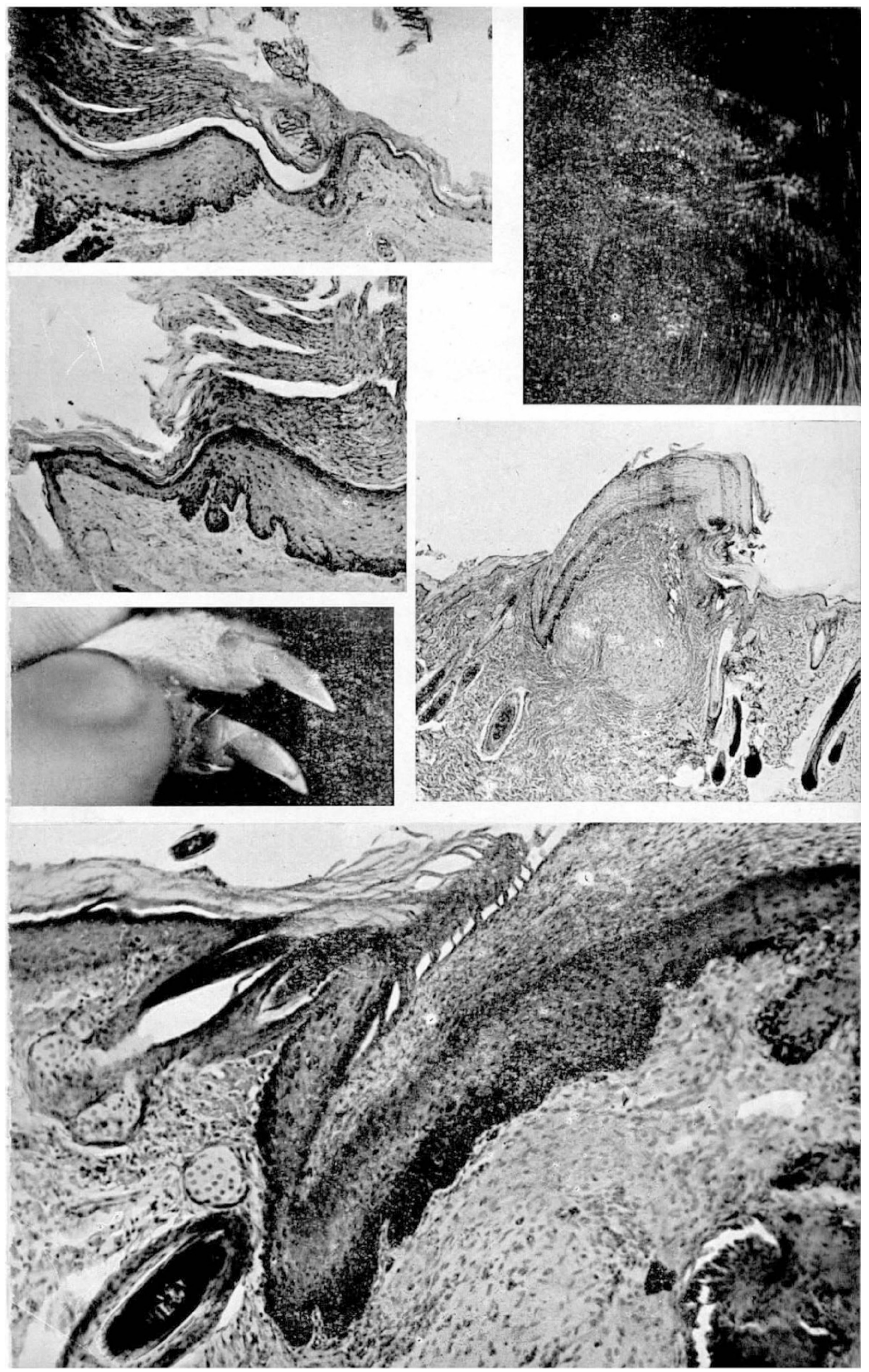
FIG. 25.-A small graft from this originally pure white sole was "infected" by transplantation to black integumentary skin, and a central portion of it was then grafted back to the sole with the aid of Elastoplast dressings. Note the spread of deep homogeneous pigmentation. The graft can just be discerned in the centre of the blackened area.
Fig. 26 ( $c f$. fig. 19).-Black sole-of-foot graft 159 days after transplantation to white chest skin. The pattern of pigment spread is characteristic of integumentary skin, and the graft continues blacker than its surroundings.
FIGs. 27, 28.-Two small tongue grafts in black body skin, both removed I 4 I days after transplantation. Even in lowpower view the characteristic tongue cuticle discloses the presence of the specific epithelium beneath it. Hæmatoxylin and eosin. $\times 40$.
FIG. 31.-Section of the graft illustrated by fig. 27 stained very lightly with orange$\mathrm{G}$ alone. Pigmentation stops dead at the tongue-skin junction : even after I $4 \mathrm{I}$ days not one tongue cell has acquired the faintest pigmentation. $\times$ I 10 .
Figs. 29, 30.-High-power photographs of the tongue-skin junctions of the grafts illustrated by figs. 27 and 28 respectively: note the abrupt transition between the two types of epithelium and the cuticles they form, and the fact that tongues epithelium lacks a stratum granulosum. Pigmentation stops abruptly at the margin (see fig. $3 \mathrm{I}$ ). Hæmatoxylin and eosin. $\times$ I 10 .

Fig. 32.-Minute black skin graft in the dorsal surface of the tongue, 72 day. after transplantation. It has neither initiated pigmentation nor lost its own. There was no perceptible change in its appearance 2 I 3 days later. 
that houses it. It fails when confronted with the critical tests outlined in section (iv) and may be challenged in its own right on two grounds.

(A) If pigmentary dendritic cells migrate from black epidermis into white, what can be supposed to happen to their non-pigmentary analogues already in residence? They occupy the exact positions into which the melanophores must be supposed to migrate, and are present in the same numbers. There is no room for both types to co-exist side-by-side ; and the application to black skin of the technique that is used to reveal the presence of non-pigmentary dendritic cells in white skin shows that the only dendritic cells present are those containing pigment granules.

(B) Pigmentary dendritic cells do not in fact migrate differentially (i.e. away from the ordinary epidermal cells) from pigmented adult skin in vivo, even when offered the most favourable opportunities for doing so. Small grafts of black skin, or of the black epidermis split away from it, have repeatedly been tucked into subcutaneous pockets ; into the spongy vascular mucosa of the tongue; and into the brain.* In all these situations the skin fragments show intense proliferation and cystic growth; but pigmentary dendritic cells were in no case found to have migrated away from the epidermis. But when an epidermal sheet moves as a whole (as it does in the resurfacing of a raw skin bed) then, of course, its dendritic cells move with it. This does not represent differential migration.

We do not claim that considerations $(A)$ and $(B)$ disqualify the melanophore migration hypothesis as decisively as, for example, the fact of serial propagation disposes of the hypothesis of diffusion, though the existence of non-pigmentary dendritic cells requires some explaining away. The evidence of the next section may, however, be thought to be decisive.

(iv) The hypothesis of an infective cellular transformation

The hypothesis runs as follows. When black skin and white are juxtaposed, "black" dendritic cells establish the same sort of cytoplasmic connection with "white" dendritic cells as blacks do with other blacks and whites do with other whites. Some cytoplasmic ingredient of the black dendritic cell then enters its white neighbour, relying on the same process as that which allows formed melanin granules to be passed from the branch of a dendritic cell into the cytoplasm of the ordinary epidermal cell on which it forms a cap. Once blackened, a white dendritic cell remains pigmentary in function thereafter, and can in its turn transform any other white dendritic cell it makes contact with. The transformation process is therefore serially transmissible.

* By means of a standard tumour-transplantation trochar passed $5 \mathrm{~mm}$. deep through a twist-drill hole of $2 \mathrm{~mm}$. bore cut through the centre of the dorsal aspect of the left parietal bone. The primary object of our series of brain transplantations was to see whether pigmentary dendritic cells could "infect" their remote cousins among the neuroglia. 
According to this hypothesis, the process of pigment spread is mediated by dendritic cells, and ordinary epidermal cells participate in it only at second hand. It differs in this respect from our original hypothesis (Billingham and Medawar, 1947a) which was put forward before the non-pigmentary dendritic cell had been discovered.

The hypothesis evidently has a complete anatomical foundation. Dendritic cells are so spaced that they can, and in fact do, make contact with each other ; either (rarely, we find) by actual confluence of branches, or by the formation of an end-cap from the process of one dendritic cell on the cell body of another. Further, dendritic cells can evidently establish a peculiar and most intimate type of contact with their neighbours, since melanin formed in the branches of a pigmentary dendritic cell comes to enter the cytoplasm of the ordinary epidermal cells in its domain-itself a process of " infection" in a literal, but trivial, sense. Moreover, the hypothesis accounts immediately for all the phenomena so far described under headings (i), (ii), and (iii).

The statement that white grafts behave in a graft-specific manner when artificially caused to blacken (e.g. that what a white claw turns into is a black claw) can now be amplified and strengthened. The rate and pattern of blackening of a white skin graft is a function of the density and distribution of white dendritic cells within it. As has already been mentioned, a white graft of body skin, with relatively few dendritic cells concentrated at the bases of its broad and shallow epidermal ridges, blackens slowly and in the coarse but even reticulate. pattern that corresponds exactly with the distribution of the ridges. The blackening of white ear skin in black body skin is, as the number and pattern of white dendritic cells within it would lead one to predict, faster and much more finely (though still perceptibly) reticulate. Finally, white sole-of-foot epithelium in black body skin blackens three or four times as fast as a graft of white body skin, and its pattern is a homogeneous deep black, corresponding to the microscopically fine grain of its epidermal ridging. Such a blackened sole-of-foot graft (plate III, figs. 19, 20, 2I) is much blacker than the black integumentary skin that transformed it-a fact impossible to explain on hypotheses (i) and (ii) and requiring a battery of subsidiary assumptions before it will submit to interpretation by (iii). Conversely, when a black sole-of-foot or vaginal graft initiates pigmentation in white body skin (plate 4, fig. 26), the pattern and density of pigmentation is in all respects skin-like, and the grafts remain characteristically blacker than their surroundings.

These histological and experimental facts represent our prima facie case for the hypothesis that pigment spread is mediated by the transformation of dendritic cells. If the hypothesis is correct, then an epidermal tissue lacking dendritic cells must permanently resist infective blackening. Alternatively, if over some stretch of an epidermal tissue dendritic cells are absent or are present in numbers 
insufficient to form a contiguous system, then that stretch must form an impenetrable barrier to the spread of infective blackening.

The tongue epidermis of the guinea-pig, lacking dendritic cells, provides a critical test of the former of these predictions. Small pinch grafts may be cut without difficulty from the dorsal or dorso-lateral aspects of the tongue and transplanted without special precautions to black skin on the chest. The fate of such grafts is easy to follow, for tongue epithelium is one of the distinct true-breeding members of the epidermal family and so conserves its graft-specific characters (e.g. thickness and packing of cuticle; absence of stratum granulosum) indefinitely on transplantation to anatomically unnatural positions (plate IV, figs. 27-30). Not one tongue-in-black skin graft of a series of which the longest was maintained to 183 days showed the faintest shadow of pigmentation either to the naked eye or in serial transverse section. An unstained section of the tongue-skin junction shows that pigmented body epidermis and non-pigmented tongue epidermis can be distinguished to a cellular interface (plate IV, fig. $3 \mathrm{I}$ ). The prediction is thus fully borne out. In the converse experiment, small black-skin grafts have been tucked under very shallow flaps in the tongue and have duly broken their way to the surface (plate IV, fig. 32). After even so long as 285 days there was no trace of pigment spread.

This converse experiment shows that tongue fails to pigment because dendritic cells are absent, not because of the existence of a hypothetical inhibitor of pigmentation. Any such inhibitor should at least perceptibly depress the pigmentation of a minute black skin graft in the tongue. In fact, it did not do so.

Ordinary integumentary skin provides a ready-made example of an epidermal tissue in which the contiguous system of dendritic cells is interrupted over a definite stretch; for it has already been stated that dendritic cells, though present in the hair bulb and in the superficial epidermis, are absent from that region of the neck of the mature follicle into which the sebaceous glands open. The follicle neck is, of course, confluent with the superficial epidermis above it and with the hair bulb sheath below. Hypothesis (iv) therefore predicts that infection can only spread in the superficial epidermis; it cannot pass down the hair follicle to the root for lack of dendritic cells to mediate its passage. This prediction corresponds exactly with observed fact: the hairs of artificially blackened white skin remain white (plate II, figs. I5-19 $^{-1}$ plate 4 , fig. 26). The small percentage of black hairs that develop in infected white skin after repeated activation by trauma or serial grafting may well represent hairs formed by follicles budded off from pigmented superficial epidermis rather than from the shafts of previously existing effete follicles.

The existence of a complete anatomical background for the cellular transformation hypothesis, one's ability to draw every experimental fact as inferences from it, and its successful emergence from two critical tests, make a strong case for its validity. 


\section{THE NATURE OF THE CELLULAR TRANSFORMATION}

As a background to a discussion of the nature of the transformation process, we wish to emphasise that the case we have been studying is quite exceptional in nature. It happens that there exists in one and the same individual a race of cells-the dendritic cells, comprising what may be called the "epidermal glial system "-subdivided into two distinct true-breeding families by a slight, though phenotypically obvious, inherited character difference. It is in effect a single specific difference, "blackness" as opposed to "whiteness," of the presenceor-absence type; i.e. it seems to satisfy the equation "pigmentary dendritic cell $=$ non-pigmentary dendritic cell + pigment-forming system." Furthermore, dendritic cells are of a peculiar histological type: they establish very intimate cytoplasmic connections with each other as well as with the ordinary epidermal cells on which the majority of their branches end. It appears, then, that the epidermis and its glial system is the only tissue complex that immediately and obviously satisfies the anatomical prerequisites for the occurrence of a cellular transformation of the "virus" type ; and furthermore that the genetical prerequisites are satisfied by the skin of spotted blackand-white guinea-pigs alone of all common experimental animals.

We may adopt, as a simplifying assumption, the hypothesis that pigmentary and non-pigmentary dendritic cells differ only in that the former possess a melanogenic enzyme system which the latter lack. The presence of this system is crudely but (when confined to epidermal tissue) specifically indicated by the dopa-reaction, which is positive in pigmentary dendritic cells alone. The simplest hypothesis that accounts for our experimental observations is that a melanogenic enzyme system capable of reproducing itself in the cytoplasm of black dendritic cells enters a neighbouring white dendritic cell in much the same way as its metabolic product, melanin, is caused to enter the ordinary epidermal cells of its own domain. Once installed in the white dendritic cell, it converts it (and its lineal descendants) to the black variant type, which can then in turn propagate the colour transformation to its white neighbours.

This hypothesis is a rough and ready first approximation, and it will be superseded in due course ; but the only ground for replacing it (save perhaps by the substitution of " self-reproducing enzyme precursor associated with nucleoprotein " for " self-reproducing enzyme" ; $c f$. Spiegelman and Kamen, I946) will be the discovery of empirical facts that lie outside its competence to explain. The position of a theory of this type in the field of cellular transformations in general, and its relevance to such problems as, for example, that of the origin of viruses, has been fully discussed by Darlington (1944), Haddow (I944), and Medawar (1947).

The writers hope to develop their experiments along two lines: (a) in an attempt, with which some technical progress has already 
been made, to bring about the transformation of white dendritic cells by cell-free extracts of black dendritic cells; and (b) in an attempt to cause black dendritic cells to undergo "mutation" to the non-pigmentary variant. This second development is of some theoretical importance, because the validity of regarding white dendritic cells as cellular genetic mutants of a pigmentary archetype turns upon it ; but, requiring as it does the simultaneous mutation of large numbers of individual cells, it may prove to be technically impossible.

Two further points remain to be discussed. The failure of black skin homografts to initiate pigment spread in white skin is hardly reconcilable with the hypothesis that pigment spread involves a serial transformation of the inductive type (Billingham and Medawar, I947a; Medawar, 1947). But it is not necessarily or obviously at odds with a theory of infective propagation; for students of transplantation immunity have been quite independently working towards the view (a) that resistance to homografts is anti-proliferative in character (Medawar, I945, I946 ; Kidd, $1946 a$ and $b$ ) ; $(b)$ that such resistance is primarily directed against sedimentable constituents of the cytoplasm, associated with nucleoprotein ( $c f$. Claude, i 943 ) and of the order of size to which our hypothetical infective particle must belong (Kidd, I $946 a)$; and $(c)$ that such sedimentable ingredients of the cell are the particular vehicles of iso-antigenic specificity (Furth and Kabat, I94I; Kidd and Friedewald, I942 $a$ and $b$; Friedewald and Kidd, I945; Kidd, I946a).

A second problem is that of the nature of the bleaching process which black skin grafts undergo in the phase of maximal cellular proliferation (see above). Similar bleaching has been sometimes observed in the healing of the donor areas of black grafts; the thickened spreading epithelium becomes white or smoky pink during the period of rapid cell division and then darkens rapidly and simultaneously over its whole surface. Examination of split graft skin shows that this is not due to the failure of melanophore division to keep pace with the division of epidermal cells; it may, however, represent a genuine "growth rate dilution" process (see Medawar, I 947) of the type first fully investigated by Preer in Paramecium (I946). It may be added that the infective transformation of, e.g. non-killer into killer variants of $P$. aurelia (Sonneborn, I943 $a$ and $b$ ) formally resembles the transformation process we have been studying, save that it acts as an instrument of cytoplasmic heredity rather than of cellular differentiation ( $c f$. Darlington, I 944 ).

\section{SUMMARY}

The paper reports a full investigation of the phenomenon of " pigment spread" in the skin of spotted black-and-white guineapigs. Four hypotheses are discussed, and three (of cellular invasion 
and replacement, simple diffusion, and melanophore migration respectively) are dismissed. The observational and experimental data are adequately explained by a fourth hypothesis, that pigment spread represents the outcome of a serially transmissible or infective transformation of the non-pigmentary dendritic cells of white epidermis into the pigmentary dendritic cells characteristic of black skin. This hypothesis leads to predictions which have been tested and confirmed. As a first approximation the infective particle is suggested to be a self-reproducing cytoplasmic enzyme or enzyme-precursor.

The special expenses involved in this research were defrayed by a grant from the Department of Plastic Surgery, Oxford University. The cost of the experimental animals was met by a grant from the Medical Research Council.

\section{REFERENCES}

BARKer, D. E. . . . . . . 1947. Arch. Path. 44, 63.

baumberger, J. P., SUntzeff, v., 1942. F. Nat. Can. Inst. 2, 413.

AND COWDRY, E. $V$.

Billingham, r. e. . . . . . 1948. 7. Anat., Lond. In the press.

BILlingham, R. E., AND MEDAWAR, 1947a. Nature 159, 1 I5.

P. B.

\begin{tabular}{|c|c|c|c|c|c|}
\hline "פ & g" & & ", & & " \\
\hline BLOCH, B. & - & - & - & - & • \\
\hline , & • & $\cdot$ & • & • & $\cdot$ \\
\hline \multicolumn{6}{|c|}{ CARNOT, P., AND DEFLANDRE, C. $Z$. } \\
\hline CLARK, W. & E. $\mathbf{L E}$ & G. & - $\quad$. & - $\quad \cdot$ & $\cdot$ \\
\hline CLAUDE, A. & - & - & - & $\cdot$ & - \\
\hline GOWDRY, E & $\mathbf{v}$. & . & . & . & . \\
\hline
\end{tabular}

DARLINGTON, C. D. . . . $\cdot$.

\section{DORRIS, $F$.}

EASTLICK, H. L.

FESSLER, A. . . . . . . .

FRIEDEWALD, W. F., AND KIDD, J. G.

FURTH, J. AND KABAT, E. A. . .

GAIRNS, F. W.

GINSBURG, B. .

HADDOW, A. M.

HAMILTON, H. Z. .

KELLEY, R. W., AND LOEB, $\mathrm{L}$.

KIDD, J. G.

,

KIDD, J. G., AND FRIEDEWALD, W. F.

" $"$ "
LAIDLAW, G. F., AND BLACKBERG,

S. N.

LANGERHANS, P. .

LEWIN, M. L., AND PECK, S. M. LOEB, $\mathbf{L}$. 1947b. Ibid. 160, 61.

1927. Fadassohns Handbook $I, 434$.

1929. Amer. F. Med. Sci. 177, 609.

1896. C.R. Soc. Biol. Paris 48, I 78 and 430 .

1936. P. Zool. Soc. i, I.

1943. Science 97, 45I.

1943. Microscopic Technique in Biology and Medicine, p. 69. Baltimore.

1944. Nature 154, 164 .

1939. F. Exp. Zool. 80, 315.

1939. Ibid. 83, 131.

1941. Brit. F. Dermatol. 53, 201.

1945. F. Exp. Med. 82, 2 I.

1941. Ibid. 74, 247.

1930. Quart. F. Micr. Sci. 74, I 5 I.

1944. Genetics 29, 176.

1944. Nature 154, 164.

I941. F. Exp. Zool. 88, 275.

1939. Anat. Rec. 74, 487.

1946a. 7. Exp. Med. 83, 227.

1946b. Cold Spring Harbor Symp. Quant. Biol. II, 94 .

1942a. 7. Exp. Med. 76,543 .

1942b. Ibid. 76,557 .

1932. Amer. F. Path. 8, 49 I.

1868. Virchow Arch. Path. Anat. 44, 325.

1941. 7. Invest. Dermatol. 4, 483.

1897. Arch. EntwMech. Org. 6, I.

1945. The Biological Basis of Individuality. Springfield. 


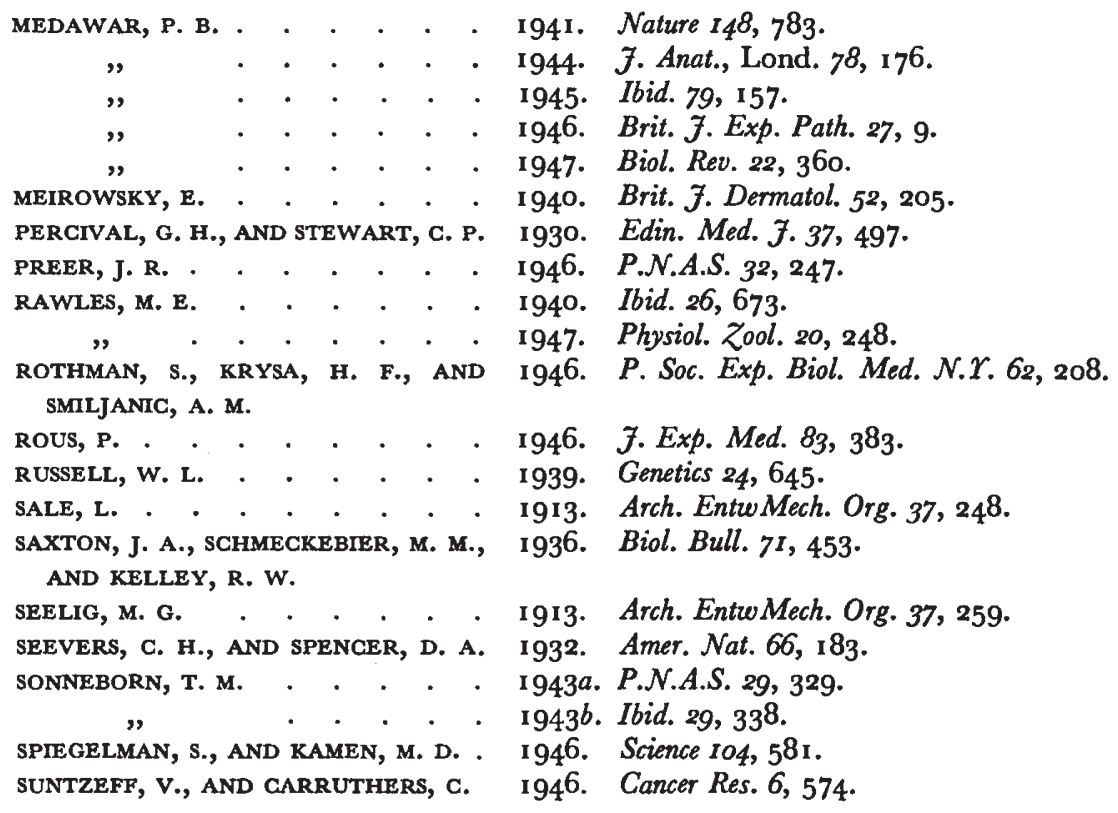

